\title{
Perfil microbiológico da colonização do sítio de inserção do cateter venoso central considerando dois curativos transparentes
}

\author{
Microbiological assessment of the colonization of a central venous catheter \\ insertion site considering two transparent dressings
}

\begin{abstract}
Gabriela Levorato Pereira ${ }^{1}$ (D), Amanda Salles Margatho ${ }^{1}$ (D), Denissani Aparecida Ferrari dos Santos Lima² (D), Bruna Nogueira dos Santos ${ }^{1}$ (D), Paula Elaine Diniz dos Reis ${ }^{3}$ (D), Aníbal Basile-Filho ${ }^{4}$ (D), Renata Cristina de Campos Pereira Silveira ${ }^{1}$ (D)
\end{abstract}

\begin{abstract}
RESUMO
Modelo do Estudo: estudo transversal da fase prospectiva de um ensaio clínico. Objetivo: identificar os microrganismos e a sensibilidade antimicrobiana no sítio de inserção do cateter venoso central coberto pelo curativo gel de clorexidina ou pelo filme transparente de poliuretano. Metodologia: estudo transversal, descritivo, realizado com adultos críticos no período de abril a dezembro de 2014 em um hospital universitário no interior do estado de São Paulo. Imediatamente após a retirada do curativo, foi coletada amostra de swab da pele do sítio de inserção do cateter, semeado em placas de Agar sangue e Agar MacConkey e incubadas em estufas bacteriológicas a $35^{\circ} \mathrm{C}$. Nas amostras que apresentaram crescimento bacteriano após 24 horas de incubação, foram realizados testes de sensibilidade aos antimicrobianos utilizando o equipamento automatizado Vitek II (Biomerieux ${ }^{\circledR}$ ). Resultados: 45 pacientes fizeram uso do curativo gel de clorexidina e 47 utilizaram o filme transparente de poliuretano. No grupo com o curativo gel de clorexidina houve crescimento dos microrganismos Acinetobacter baumannii, Pseudomonas aeruginosa, Morganella morganii, Enterobacter cloacae, Staphylococcus aureus e Staphylococcus epidermidis em 13 amostras de swabs. O Staphylococcus aureus apresentou resistência a oxacilina. No grupo do filme transparente de poliuretano seis amostras foram positivas com o crescimento de Serratia marcescens, Acinetobacter baumannii, Staphylococcus epidermidis, Staphylococcus haemolyticus e Klebsiella pneumoniae, esta resistente a amicacina (Klebsiella pneumoniae carbapenemase - KPC). Conclusão: os resultados demonstram maior crescimento bacteriano no sítio de inserção do cateter venoso central coberto pelo curativo gel de clorexidina quando comparado ao filme transparente de poliuretano.
\end{abstract}

Palavras-chave: Cateteres Venosos Centrais; Bandagens; Curativos Oclusivos; Microbiologia.

\begin{abstract}
Study design: a prospective, cross-sectional study. Objectives: identify microbiological growth at the insertion site of the central venous catheter covered by a chlorhexidine impregnated dressing or a transparent polyurethane dressing, and identify antimicrobial sensitivity. Methods: immediately after dressing removal, a skin swab was collected from the catheter insertion site and seeded in blood agar plates and MacConkey agar, then incubated in bacteriological incubators at $35^{\circ} \mathrm{C}$. After 24 hours, the plates were analyzed to verify the presence of microbial growth. In the samples that displayed microbial growth, the identification and the sensitivity test were performed using the automated equipment Vitek II (Biomerieux ${ }^{\circledR}$ ). Results: A total of 45 patients were treated with chlorhexidine impregnated dressing and 47 with transparent polyurethane dressing. In the chlorhexidine dressing group, 13 swabs samples presented with microbial growth of the following bacterial populations: Acinetobacter baumannii, Pseudomonas aeruginosa, Morganella morganii, Enterobacter cloacae, Staphylococcus aureus, and Staphylococcus epidermidis. Staphylococcus aureus presented resistance to oxacillin. In the transparent polyurethane dressing group, six samples were positive for the growth of Serratia marcescens, Acinetobacter baumannii, Staphylococcus epidermidis, Staphylococcus haemolyticus, and amikacin resistant Klebsiella pneumoniae (Klebsiella pneumoniae carbapenemase - KPC). Conclusion: The results demonstrate higher bacterial growth in the chlorhexidine impregnated dressing compared to the transparent polyurethane dressing.
\end{abstract}

Keywords: Central Venous Catheters; Dressing; Occlusive Dressings; Microbiology.

1. Departamento de Enfermagem Geral e Especializada, Escola de Enfermagem de Ribeirão Preto, Universidade de São Paulo (EERP-USP), Ribeirão Preto (SP), Brasil.

2. Departamento de Medicina Interna, Faculdade de Medicina de Ribeirão Preto, Universidade de São Paulo (FMRP-USP), Ribeirão Preto (SP), Brasil.

3. Departamento de Enfermagem, Faculdade de Ciências da Saúde, Universidade de Brasília (UnB), Brasília (DF), Brasil.

4. Departamento de Cirurgia e Anatomia, FMRP-USP, Ribeirão Preto (SP), Brasil.

$\triangle$ Renata Cristina de Campos Pereira Silveira. Avenida dos Bandeirantes, 3900 - Campus Universitário - Bairro Monte Alegre. CEP: $14040-902$. Ribeirão Preto (SP) Brasil. recris@eerp.usp.br | Recebido em: 23/10/2019 | Aprovado em: 04/06/2020 


\section{INTRODUÇÃO}

Os Cateteres Venosos Centrais (CVC) são amplamente utilizados no cenário hospitalar, sendo necessários para a administração de infusão intravenosa, retirada de sangue e monitorização hemodinâmica. Seu uso pode acarretar sérias complicações infecciosas como a Infecção da Corrente Sanguínea Relacionada ao Cateter (ICSRC) que eleva a permanência hospitalar, o aumento dos custos e a mortalidade ${ }^{1}$.

O principal mecanismo de patogênese das ICSRC do CVC de curta permanência é a migração de microrganismos da pele ao redor do sítio de inserção para a ponta do cateter ${ }^{2}$. O cuidado com o curativo de CVC é uma ação de enfermagem essencial para a proteção do sítio de inserção. O curativo reduz a ocorrência de colonização da pele por microrganismos ${ }^{3,4}$.

Originalmente a cobertura do sítio de inserção era realizada apenas com gaze estéril e fita adesiva. A aplicação do filme transparente de poliuretano (FTP) surgiu como uma nova tecnologia de cobertura, agregando ao cuidado com o CVC maior segurança, pois melhora a aderência na pele e a visibilidade do sítio de inserção, diminuindo a frequência de manipulação, além de ser uma barreira eficaz contra microrganismos ${ }^{3}$.

Em uma revisão sistemática, identificou-se que o curativo com gaze estéril e fita adesiva aumentou em quatro vezes a ocorrência de ICSRC quando comparado ao FTP, contudo, os estudos primários incluídos na revisão eram pequenos e não permitiram confirmar superioridade de um curativo com relação ao outro na prevenção das infecções relacionadas ao cateter ${ }^{3}$.

O curativo gel de clorexidina (CGCHX) surgiu como uma nova tecnologia aplicada ao cuidado do sítio de inserção do cateter que contém $2 \%$ de clorexidina em gel translúcido e apresenta liberação contínua do antisséptico na pele para reduzir a atividade microbiana ao redor do sítio de inserção ${ }^{5,6}$. Bashir et al. confirmaram que com o uso do CGCHX as contagens de bactérias na pele após a antissepsia mantiveram-se baixas ${ }^{5}$.

Uma metanálise que comparou o uso dos curativos impregnados com clorexidina com outros curativos apontou na direção de menores ocorrências de infecções relacionadas ao CVC com o uso dos curativos impregnados com clorexidina?. Em nenhum dos nove estudos analisados foi reportada a resistência a clorexidina, os microrganismos mais isolados foram os gram-positivos?.

Diante das evidências relacionadas aos dois tipos de curativos e sua efetividade na prevenção de infecções de corrente sanguínea relacionadas ao cateter, busca-se estudar e conhecer especificamente $o$ local de inserção do cateter, onde ocorre a quebra de barreira cutânea e onde os curativos são aplicados.

Este estudo teve por objetivo identificar os microrganismos e a sensibilidade antimicrobiana no sítio de inserção do cateter venoso central coberto pelo curativo gel de clorexidina ou pelo filme transparente de poliuretano.

A relevância desse estudo se dá pelo tipo de desfecho primário, pois se o curativo tem efeito direto sobre a pele do paciente ao redor do sítio de inserção, para avaliar sua efetividade deve-se analisar o crescimento microbiológico na pele.

\section{METODOLOGIA}

Trata-se de um estudo quantitativo com abordagem descritiva da análise do uso do CGCHX e do FTP utilizado em CVC de curta permanência, ou seja, temporário, não tunelizado e não totalmente implantado ${ }^{1}$, em pacientes adultos críticos.

Este estudo é um recorte transversal de um ensaio clínico aleatorizado ${ }^{8}$ cujos participantes foram alocados no grupo experimental (denominado grupo de clorexidina gel) e controle (grupo poliuretano). Os dados relacionados à avaliação do curativo, avaliação da pele e swab da pele do sítio de inserção do cateter dos dois grupos foram utilizados para o presente estudo.

O estudo foi realizado na Unidade de Terapia Intensiva (UTI) e Unidade Coronariana (UCO) de um hospital universitário de alta complexidade localizado no interior do estado de São Paulo. As duas unidades são compostas por 14 leitos.

A coleta dos dados foi realizada no período de abril a dezembro de 2014. Os critérios de inclusão foram: pacientes admitidos na UTI ou UCO; com idade igual ou superior a 18 anos; que tinham um CVC percutâneo inserido em veias subclávia, femoral ou jugular; que a expectativa de permanência do CVC fosse de pelo menos 48 horas. Os critérios de exclusão foram: paciente com cateter impregnado com antimicrobiano; com alergia ou hipersensibilidade a 
qualquer um dos componentes dos curativos; com lesões ativas na pele ao redor do sítio de inserção.

Para recrutamento dos participantes, os pesquisadores encarregados pela pesquisa realizavam visitas diárias nas duas unidades e avaliavam o paciente quanto ao potencial de elegibilidade.

Antes de iniciar o estudo os enfermeiros das duas unidades foram treinados para realizar a inserção e retirada de ambos os curativos, assim como coletar o swab da pele antes da retirada do CVC. Para tanto, foi ministrada uma aula teórica com aproximadamente 20 minutos, prática em boneco com CVC e em seguida aplicado um pós-teste. Todos os enfermeiros foram considerados aptos após $100 \%$ de acerto no pós-teste. Os 13 enfermeiros da UTI e UCO consentiram em participar do treinamento e da coleta de dados.

A inserção do CVC era realizada segundo as recomendações dos Centers for Disease Control and Prevention $(C D C)^{2}$. Os médicos que realizavam o procedimento utilizaram barreira máxima de proteção (uso de gorro, máscara, avental estéril de manga longa, campos estéreis, luvas estéreis e realizavam a lavagem cirúrgica das mãos antes da inserção), e quando possível, o acesso na veia femoral era evitado. Conforme rotina da unidade, os pacientes tomavam banho com clorexidina degermante a $2 \%$ diariamente.

De acordo com o protocolo da unidade, nas primeiras 24 horas após a inserção do cateter, o curativo era realizado com gaze estéril e fita adesiva. Assim que cessasse o sangramento do sítio de inserção, 0 curativo era realizado de acordo com o grupo aleatorizado: filme transparente de poliuretano ou curativo gel de clorexidina. Os curativos foram adquiridos através de recurso dos pesquisadores envolvidos, não havendo conflito de interesse com a empresa.

As trocas dos curativos eram realizadas a cada sete dias, conforme recomendado na literatu$\mathrm{ra}$, denominadas trocas programadas. Aquelas que ocorriam antes desse período, denominadas trocas não programadas, eram devido ao descolamento do curativo, sujidade e/ou umidade ${ }^{2}$. Durante as trocas dos curativos era realizada antissepsia da pele com clorexidina alcoólica a 0,5\%.

Diariamente os pesquisadores avaliavam os curativos, a pele ao redor do sítio de inserção e as condições clínicas dos pacientes. Os dados eram documentados em instrumentos previamente elaborados e avaliados com relação ao conteúdo e aparência por cinco juízes, todos enfermeiros, sen- do três assistenciais que trabalhavam em UTI e dois docentes especialistas no tema e método.

O seguimento dos pacientes se dava até a retirada do CVC. Neste momento, imediatamente após a remoção do CGCHX ou do FTP os enfermeiros das unidades realizavam a coleta do swab de pele. O swab era umedecido em solução fisiológica estéril, rolado por uma área de cerca de $3 \mathrm{~cm}^{2}$ ao redor do sítio de inserção do cateter e inserido em tubo estéril para transporte com meio STUART (COPAN ${ }^{\circledR}$ ).

As amostras foram analisadas no laboratório de microbiologia, onde foram semeadas em placas de Agar sangue e Agar MacConkey e incubadas em estufas bacteriológicas a $35^{\circ} \mathrm{C}$. Após 24 horas de incubação as placas foram analisadas para verificar a presença ou não de crescimento de microrganismos. Nas amostras que apresentaram crescimento bacteriano a identificação e o teste de sensibilidade foram realizados utilizando o equipamento automatizado $\mathrm{Vi}$ tek II (Biomerieux ${ }^{\circledR}$ ).

As variáveis relacionadas à cultura de pele analisadas foram:

- Colonização da pele: crescimento semi-quantitativo positivo de mais de 15 unidades formadoras de colônia (UFC) na cultura da pele ao redor do sítio de inserção, com ou sem concomitância de ICS ${ }^{2}$.

- Identificação dos microrganismos.

- Perfil de sensibilidade dos microrganismos: a sensibilidade ou resistência dos microrganismos gram-positivos foram testadas quanto aos antimicrobianos rifampicina, penicilina, oxacilina, clindamicina, eritromicina, gentamicina, ciprofloxacino, tigeciclina, trimetoprima/sulfametoxazol, vancomicina, teicoplanina, linezolida, moxifloxacino e norfloxacino.

Para verificar a sensibilidade ou resistência dos microrganismos gram-negativos testou-se quanto aos antimicrobianos ampicilina, ampicilina/sulbactam, cefoxitina, axetilcefuroxima, cefuroxima, ceftriaxona, ceftazidima, cefepime, amicacina, gentamicina, ciprofloxacino, meropenem, ertapenem, tigeciclina, piperacilina/tazobactam, colistina e imipenem.

As variáveis relacionadas ao perfil demográfico e clínico dos pacientes e relacionadas ao CVC foram: idade, sexo, unidade de internação, APACHE II, dias de internação, categoria de admissão, número de lúmens, veia de inserção, tempo de per- 
manência, e motivos de remoção do CVC. As variáveis relacionadas ao uso do curativo e as características clínicas da pele do paciente foram: número de trocas programadas e não programadas.

Os dados coletados foram processados no programa Statistical Package for the Social Sciences (IBM-SPSS) software (versão 24.0 para Windows ${ }^{\circledR}$ ) para a análise estatística. Foi realizada análise descritiva para todas as variáveis. O teste Qui-quadrado foi utilizado para comparar a colonização da pele entre os grupos CGCHX e FTP. Foi aplicado o teste de Mann-Whitney para comparar a quantidade de trocas de curativos e tipos de trocas dos pacientes com colonização positiva e negativa de pele nos grupos CGCHX e FTP. Para as análises estatísticas, considerou-se o nível de significância $a=0,05$.

Por se tratar de um projeto de pesquisa com objetivos diferentes ao ensaio clínico aleatorizado, o projeto foi submetido e aprovado separadamente pelo Comitê de Ética e Pesquisada da Escola de Enfermagem de Ribeirão Preto da Universidade de São Paulo com ciência e acordo do Comitê de Ética da instituição coparticipante sob CAAE número 33941714.8.0000.5

Ao atender os critérios de inclusão, foi solicitada a assinatura do termo de consentimento livre e esclarecido pelos pacientes com Escala de Coma de Glasgow $<8$. Se o paciente estivesse sob ventilação mecânica ou apresentasse a Escala de Coma de Glasgow $\leq 8$, era solicitado a autorização ao familiar responsável para que o paciente fosse incluído no estudo. Nenhum dos participantes ou familiares negou-se a participar do estudo ou pediu para que descontinuasse o uso dos curativos.

\section{RESULTADOS}

Foram incluídos no estudo 115 pacientes, porém, a amostra final foi composta por 92 pacien- tes, sendo que 45 pacientes receberam o $\mathrm{CGCHX}$ e 47 pacientes o FTP conforme descrito na Figura 1.

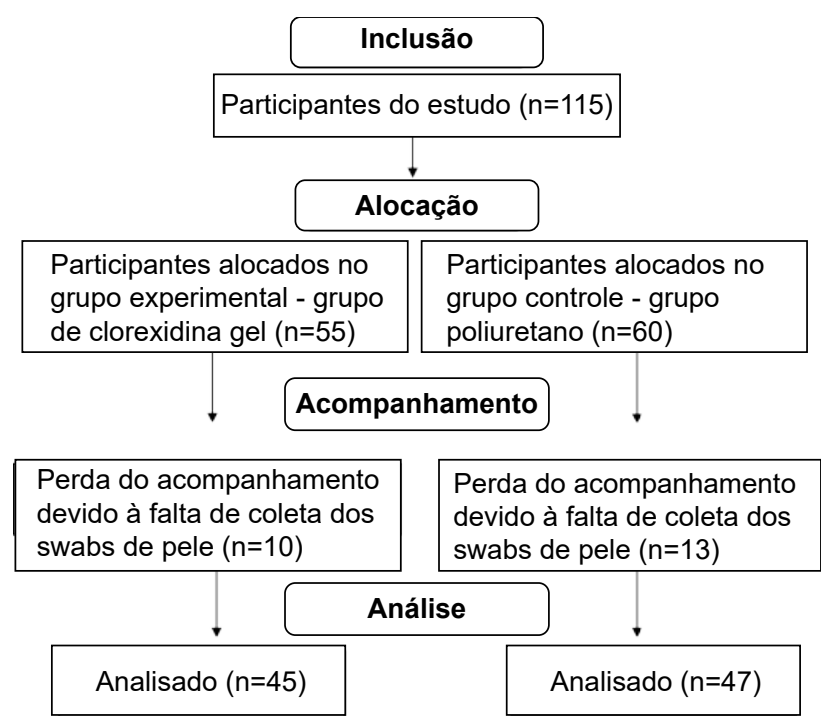

Figura 1: Fluxograma de inclusão, alocação, acompanhamento e análise dos participantes do estudo, 2019, Ribeirão Preto.

A descrição desses pacientes e as características relacionadas ao CVC são apresentadas na Tabela 1.

Dos 45 cateteres acompanhados com CGCHX foram registradas 94 remoções dos curativos, sendo que $88,3 \%(n=83)$ foram trocas não programadas e $11,75 \%(n=11)$ foram trocas programadas.

Para o grupo em uso do FTP foram avaliadas 114 remoções de curativos, dentre as quais $96,6 \%$ $(n=109)$ foram não programadas e $4,4 \%(n=5)$ foram programadas.

Ao se comparar a colonização da pele e os microrganismos identificados nas culturas nos dois tipos de curativos não foi identificada diferença estatisticamente significante (Tabela 2 ).

\section{Tabela 1}

Características relacionadas ao perfil demográfico, clínico e relacionadas ao cateter venoso central por tipo de curativo, 2019, Ribeirão Preto.

\begin{tabular}{lcc}
\hline \multirow{2}{*}{ Características } & \multicolumn{2}{c}{ Tipo de Curativo } \\
\cline { 2 - 3 } & $\mathrm{CGCHX}(\mathrm{n}=45)$ & $\mathrm{FTP}(\mathrm{n}=47)$ \\
\hline Idade, média (DP) & $57,0(15,9)$ & $58,0(17,3)$ \\
Sexo, \% feminino $(\mathrm{n})$ & $46,7(21)$ & $57,4(27)$ \\
\hline
\end{tabular}


Tabela 2 (Continuação)

\begin{tabular}{|c|c|c|}
\hline \multirow{2}{*}{ Características } & \multicolumn{2}{|c|}{ Tipo de Curativo } \\
\hline & $\mathrm{CGCHX}(n=45)$ & FTP $(n=47)$ \\
\hline \multicolumn{3}{|l|}{ Unidade de internação, \% (n) } \\
\hline UTI & $95,6(43)$ & $83,0(39)$ \\
\hline UCO & $4,4(2)$ & $17,0(8)$ \\
\hline Apache II, média (DP) & $26,7(8,7)$ & $24,1(8,0)$ \\
\hline Dias de internação, média (DP) & $11,0(10,8)$ & $13,0(14,7)$ \\
\hline \multicolumn{3}{|l|}{ Categoria de admissão, \% (n) } \\
\hline Clínica & $86,7(39)$ & $80,9(38)$ \\
\hline Cirúrgica & $13,3(6)$ & $19,1(9)$ \\
\hline \multicolumn{3}{|l|}{ Número de Lúmens, \% (n) } \\
\hline Duplo Lúmen & $82,2(37)$ & $95,7(45)$ \\
\hline Triplo Lúmen & $17,8(8)$ & $4,3(2)$ \\
\hline \multicolumn{3}{|l|}{ Veia de Inserção, \% (n) } \\
\hline Jugular & $53,3(24)$ & $68,1(32)$ \\
\hline Subclávia & $40,0(18)$ & $25,5(12)$ \\
\hline Femoral & $6,7(3)$ & $6,4(3)$ \\
\hline Tempo de permanência do CVC em dias, média (DP) & $7,0(4,9)$ & $7,0(4,5)$ \\
\hline Mediana (Min, Max) & $6,0(2,23)$ & $6,0(1,18)$ \\
\hline \multicolumn{3}{|l|}{ Motivos remoção do CVC, \%(n) } \\
\hline Fim de tratamento & $40,0(18)$ & $53,2(25)$ \\
\hline Óbito do paciente & $35,6(16)$ & $21,3(10)$ \\
\hline Suspeita Infecção relacionada ao CVC & $24,4(11)$ & $19,1(9)$ \\
\hline \multicolumn{3}{|l|}{ Duração do curativo (dias) } \\
\hline Até 3 dias & $60 *$ & $86 *$ \\
\hline 4 dias ou mais & $34 *$ & $28 *$ \\
\hline
\end{tabular}

DP: desvio padrão; Outros motivos de remoção do CVC: obstrução, paciente sacou o cateter, posicionamento incorreto do cateter por tração.

*Valores correspondentes ao total de trocas do curativo, sendo 94 no grupo CGCHX e 114 no grupo FTP.

\section{Tabela 2}

Variáveis relacionadas aos resultados das culturas de pele no sítio de inserção do cateter venoso central por tipo de curativo, 2019, Ribeirão Preto.

\begin{tabular}{lcc}
\hline & \multicolumn{2}{c}{ Tipo de Curativo } \\
Variáveis & $\begin{array}{c}\text { CGCHX } \\
(\mathrm{n}=45)\end{array}$ & $\begin{array}{c}\text { FTP } \\
(\mathrm{n}=47)\end{array}$ \\
\hline Colonização da pele, \% $(\mathrm{n})$ & $28,9(13)$ & $12,8(6)$ \\
Tipo de Microrganismo & & $32,06 *$ \\
Nenhum & 7 & 1 \\
Staphylococcus epidermidis & - & 1 \\
Staphylococcus epidermidis e Staphylococcus haemolyticus & 1 & - \\
Staphylococcus aureus & 2 & 1 \\
Acinetobacter baumannii & 2 & 1 \\
\hline
\end{tabular}

(Continua...) 
Tabela 2 (Continuação)

\begin{tabular}{lcc}
\hline & \multicolumn{2}{c}{ Tipo de Curativo } \\
Variáveis & $\begin{array}{c}\text { CGCHX } \\
(\mathrm{n}=45)\end{array}$ & $\begin{array}{c}\text { FTP } \\
(\mathrm{n}=47)\end{array}$ \\
\hline Pseudomonas aeruginosa & 1 & - \\
Morganella morganii & 1 & - \\
$\begin{array}{l}\text { Acinetobacter baumannii, Morganella morganii } \\
\text { e Enterobacter cloacae } \\
\text { Klebsiella pneumoniae }\end{array}$ & 1 & 1 \\
Serratia marcescens & - & $* *$ \\
Acinetobacter baumannii e Klebsiella pneumoniae & - & 1 \\
\hline
\end{tabular}

${ }^{*}$-valor obtido teste qui-quadrado; ${ }^{* *}$ não se aplica

Para comparar o número de trocas entre colonização positiva e negativa considerando cada tipo de curativo separadamente foi utilizado o Teste de Mann-Whitney e os dados estão descritos na Tabela 3.

Dentre 45 culturas de swabs coletadas nos pacientes em uso do CGCHX, 13 (28,9\%) apresentaram o crescimento de microrganismos, sendo oito gram-positivos (S. epidermidis e $S$. aureus) e cinco gram-negativos ( $A$. baumannii, $M$. morganii, E. cloacae e $P$. aeruginosa). Dentre 47 culturas de swabs coletadas nos pacientes em uso do FTP, seis $(12,8 \%)$ apresentaram o crescimento de microrganismos, sendo dois gram-positivos (S. epidermidis, S. haemolyticus) e quatro gram-negativos (S. marcescens, K. pneumoniae, A. baumannii).

$O$ perfil de sensibilidade dos microrganismos identificados nas amostras de swabs da pele dos pacientes em uso dos curativos CGCHX e do FTP como cobertura do sítio de inserção do cateter venoso central está apresentado na Figura 2 (gram-positivos) e na Figura 3 (gram-negativos).

\section{Tabela 3}

Comparação do número de trocas entre colonização positiva e negativa considerando cada tipo de curativo separadamente, 2019, Ribeirão Preto.

\begin{tabular}{|c|c|c|c|c|c|c|c|}
\hline \multirow[b]{2}{*}{ Variáveis } & \multirow[b]{2}{*}{ Colonização } & \multicolumn{2}{|c|}{ CGCHX $(n=45)$} & \multirow[b]{2}{*}{ Valor-p* } & \multicolumn{2}{|c|}{ FTP $(n=47)$} & \multirow[b]{2}{*}{ Valor-p* } \\
\hline & & $\begin{array}{c}\text { Mediana } \\
\text { (Q1 - Q3) }\end{array}$ & Min - Máx & & $\begin{array}{c}\text { Mediana } \\
\text { (Q1 - Q3) }\end{array}$ & Min - Máx & \\
\hline \multirow{2}{*}{ Trocas programadas } & Negativa & $1(1-2)$ & $1-2$ & \multirow{2}{*}{0,38} & $1(1-1)$ & $1-2$ & \multirow{2}{*}{0,63} \\
\hline & Positiva & $1(1-1)$ & $1-2$ & & $1(1-1)$ & $1-2$ & \\
\hline \multirow{2}{*}{ Trocas não programadas } & Negativa & $1(1-2)$ & $0-5$ & \multirow{2}{*}{0,76} & $2(1-3)$ & $0-10$ & \multirow{2}{*}{0,93} \\
\hline & Positiva & $1(1-2)$ & $0-7$ & & $1(1-5)$ & $1-7$ & \\
\hline
\end{tabular}

*Teste de Mann-Whitney 


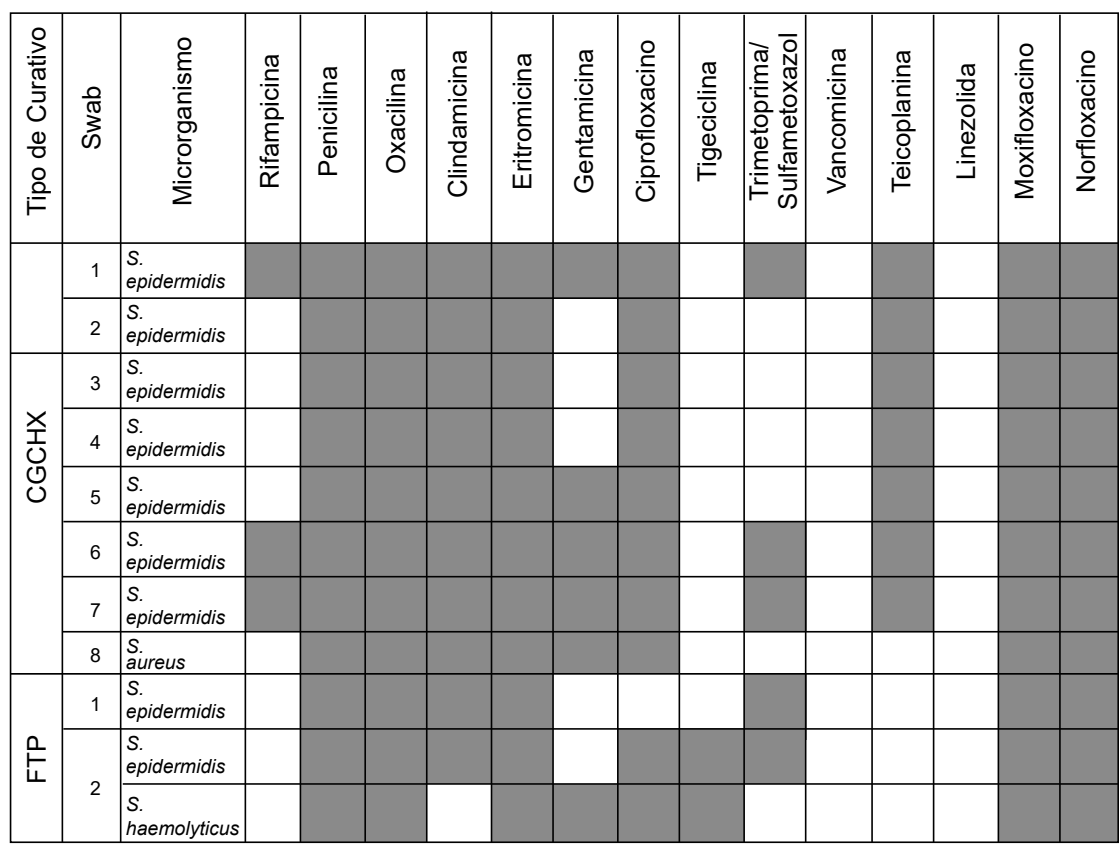

\begin{tabular}{l|l|l|l}
\cline { 2 - 3 } Legenda: & Resistente & Sensível & $\begin{array}{l}\text { CGCHX: curativo gel de clorexidina } \\
\text { FTP: filme transparente de poliuretano }\end{array}$ \\
\cline { 2 - 3 }
\end{tabular}

Figura 2: Perfil de sensibilidade dos microrganismos gram-positivos encontrados nas amostras de swabs da pele dos pacientes em uso de CGCHX e FTP como cobertura do sítio de inserção do cateter venoso central, 2019, Ribeirão Preto.

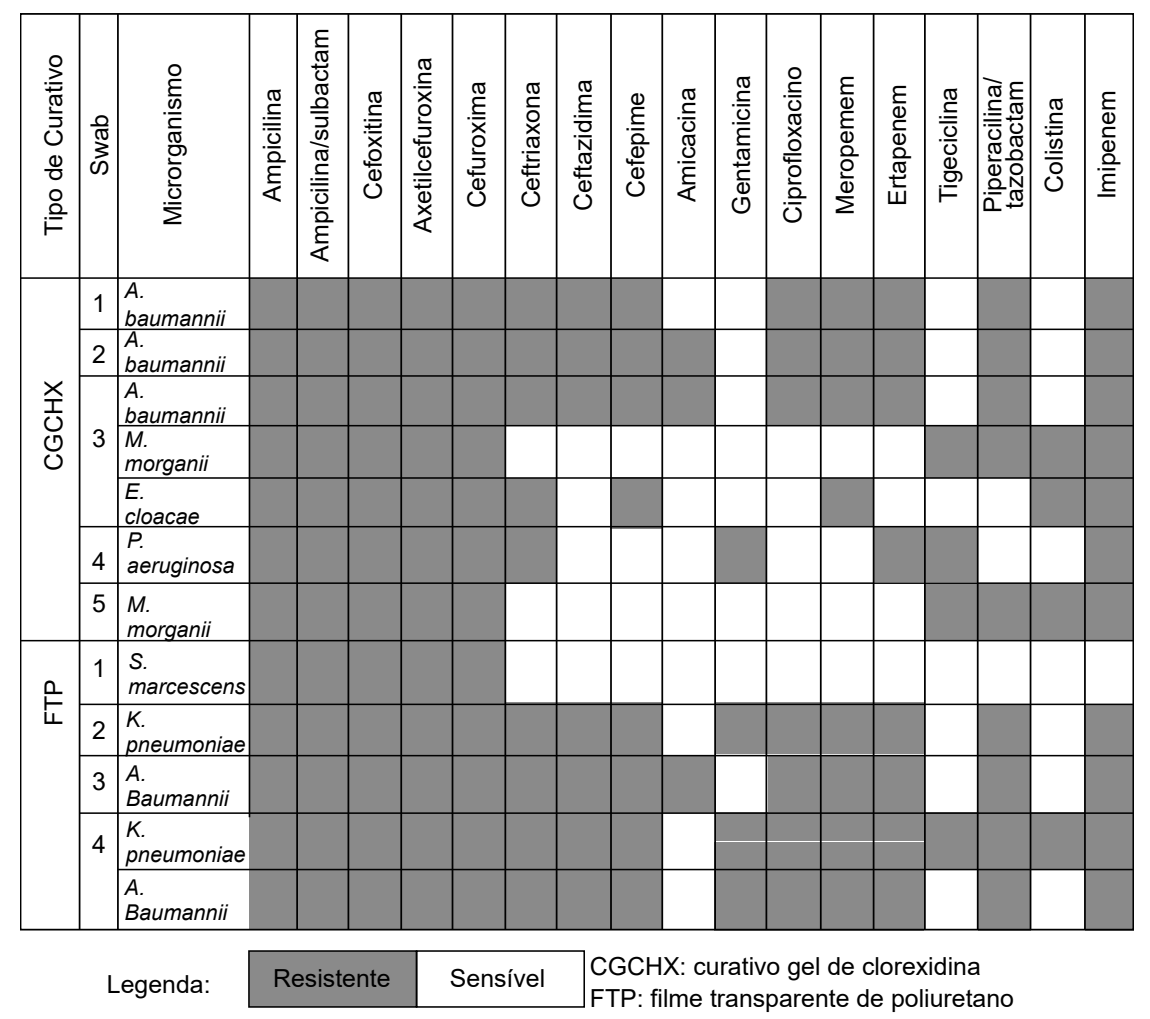

Figura 3: Perfil de sensibilidade dos microrganismos gram-negativos encontrados nas amostras de swabs da pele dos pacientes em uso de CGCHX e FTP como cobertura do sítio de inserção do cateter venoso central, 2019, Ribeirão Preto. 


\section{DISCUSSÃO}

Este estudo analisou a colonização da pele do sítio de inserção do CVC de curta permanência após o uso do curativo gel de clorexidina e do filme transparente de poliuretano em pacientes críticos.

Identificou-se que o número de casos de coIonização de pele foi maior em pacientes que utilizaram o CGCHX quando comparado àqueles que usaram o FTP, embora a diferença não tenha sido estatisticamente significante.

Esse resultado contradiz os achados da literatura ${ }^{9,10}$ que demonstram superioridade do CGCHX na redução da colonização da pele do sítio de inserção do cateter.

Um estudo realizou culturas microbiológicas de 78 CGCHX aplicados no sítio de inserção do CVC de 43 pacientes e não identificou crescimento de bactéria viável nos curativos ou nos swabs de pele analisados. Em contraste, 24 FTP e swabs de pele aplicados em 137 pacientes tiveram o crescimento de 34 bactérias viáveis ${ }^{10}$.

Um estudo observacional realizou culturas dos curativos FTP e CGCHX detectando o crescimento bacteriano em $100 \%(n=27)$ dos FTP e em 3,8\% $(n=1)$ dos CGCHX. Assim, 63\% $(n=17)$ dos microrganismos que cresceram nos FTP eram gram-negativos e no único CGCHX que apresentou crescimento bacteriano, o microrganismo era gram-positivo. O estudo infere que o CGCHX é capaz de controlar quase todo tipo de crescimento bacteriano no sítio de inserção do cateter, inclusive de bactérias gram-negativas e possivelmente é o curativo mais efetivo para prevenção de ICSRC, enquanto os curativos semipermeáveis, como o FTP, não são suficientes para prevenção de infecção por bactérias gram-negativas ${ }^{9}$.

Corroborando com esses dados, neste estudo as bactérias identificadas nos swabs do sítio de inserção do cateter cobertos com CGCHX eram, em sua maioria, gram-positivas (8/13), enquanto a maioria das bactérias que colonizaram o sítio de inserção do cateter dos pacientes em uso do FTP era gram-negativas (4/6).

Alguns fatores como o tempo de permanência do FTP e a predominância do sexo feminino dentre os pacientes em uso do FTP podem ter contribuído para um menor crescimento bacteriano na pele coberta por este curativo. Em um estudo sobre a avaliação do efeito bactericida dos CGCHX comparado ao FTP em indivíduos saudáveis, os resultados revelaram um fato preocupante em relação ao FTP que é o crescimento bacteriano na pele quando o tempo de permanência do curativo foi superior a quatro dias ${ }^{11}$. Dentre os 114 curativos de FTP trocados nos 47 pacientes avaliados neste estudo, $86(75 \%)$ foram removidos em um período inferior a quatro dias após sua aplicação, o que indica que os curativos de FTP permaneceram fixados por pouco tempo, necessitando trocas frequentes, o que pode ter levado à menor colonização bacteriana dos curativos de FTP. Além disso, a maioria dos pacientes em uso do CGCHX era do sexo masculino e tiveram seus cateteres inseridos na veia jugular. É sabido que os homens apresentam risco dobrado de colonização cutânea devido à presença de barba na região da inserção jugular, o que dificulta a limpeza da pele e fixação do curativo ${ }^{12}$.

A maioria dos achados da literatura em relação ao CGCHX tratam da sua capacidade de redução de infecção de corrente sanguínea relacionada ao cateter ou redução de colonização do $\mathrm{CVC}^{4,9,10,13-20 .}$

Dois estudos recentes ${ }^{13,16,20}$ demonstraram que os curativos impregnados com clorexidina reduzem as taxas de infecção relacionada ao cateter ou o risco de colonização de cateter venoso central, porém com algumas ressalvas.

Wei et al., 2019 conduziram uma metanálise de 12 ensaios clínicos randomizados com 6028 pacientes para comparar o CGCHX com outros ou nenhum tipo de curativo como prevenção de complicações relacionadas ao cateter. $O$ autor observou que o CGCHX foi benéfico na redução do risco de colonização do cateter nos ensaios clínicos com tamanho amostral superior a 200 pacientes, porém essa diferença não foi encontrada nos ensaios clínicos avaliados com amostra menor que 200 , indicando que o tamanho da amostra é um importante fator de influência do resultado. Além disso, o autor não analisou seus resultados considerando fatores importantes como a frequência das trocas do curativo, considerando os resultados de colonização do cateter incertos. Nosso estudo contou com um tamanho amostral de 92 pacientes, o que pode ter influenciado no resultados de colonização do sítio de inserção dos cateteres cobertos com CGCHX.

Gerçeker et al., 2017 conduziram um estudo prospectivo controlado randomizado mono-cego, 
comparando bundles de cuidados do CVC envolvendo o CGCHX e o FTP para prevenção de infecção de corrente sanguínea relacionada ao cateter. Os autores encontraram uma redução de $50 \%$ das taxas de infecção no grupo do CGCHX e $43 \%$ no grupo do FTP, porém concluíram que embora tenha encontrado redução das taxas de infecção quando comparados os dois grupos, a diferença não é estatisticamente significante e, portanto, o bundle envolvendo o CGCHX não foi mais efetivo que o bundle que continha o FTP na prevenção de infecção de corrente sanguínea relacionada ao cateter.

Cabe ressaltar que estes estudos citados referem-se à colonização do cateter venoso central, o que difere deste estudo que avaliou a colonização da pele do sítio de inserção do cateter, esta que se trata de um fenômeno comum com pouca relação com a colonização da ponta do cateter e, portanto, não se recomenda o uso das culturas de pele para antecipar ou excluir infecções relacionadas ao cateter ${ }^{12}$.

Além dos curativos transparentes descritos neste estudo, outras estratégias podem ser utilizadas para evitar o crescimento bacteriano desde 0 momento da inserção do cateter, realizando-a sob técnica asséptica, antissepsia da pele com clorexidina alcoólica de concentração maior que 0,5\%, com barreira máxima (máscara, gorro, luvas estéreis, avental estéril e cobrir todo o paciente com campo estéril) e escolhendo o sítio de inserção mais adequado. O curativo de cobertura do sítio de inserção do cateter deve ser trocado sempre que estiver molhado, sujo ou solto. Assim que o cateter não se faz mais necessário, este deve ser removido. Além disso, manter a equipe de saúde treinada e atualizada são maneiras de prevenir infecção em cateteres venosos centrais ${ }^{6,21}$.

Um achado que reforça o quanto é comum a colonização cutânea do sítio de inserção do cateter é o fato de que o microrganismo mais encontrado nas culturas foi o Staphylococcus epidermidis. Estudos de revisão sistemática e metanálise também reportaram que o Staphylococcus epidermidis como o microrganismo mais encontrado ${ }^{4,7}$.

Um estudo que comparou a susceptibilidade de antimicrobianos e do antisséptico clorexidina a diferentes bactérias ${ }^{22}$ detectou forte correlação entre a resistência bacteriana à clorexidina e a determinados antimicrobianos, tais como beta-lactâmicos, quinolonas e aminoglicosídeos, concluindo que a suscetibilidade bacteriana aos antimicrobianos também sugere suscetibilidade à clorexidina.

Um dado preocupante em relação às bactérias identificadas neste trabalho é o crescimento do Staphylococcus aureus resistente à oxacilina no grupo dos pacientes em uso do CGCHX. A resistência de um microrganismo tão comum no nosso cotidiano diminui as opções terapêuticas e contribui para o prolongamento do período de internação gerando maior custo para a instituição hospitalar além das possibilidades de o paciente adquirir outras infecções ${ }^{23}$.

Além da possível resistência das bactérias à clorexidina ${ }^{9}$, uma alta porcentagem de genes indicativos de tolerância à clorexidina (Qac-positivo) na pele do sítio de inserção do cateter de pacientes foi identificada no sítio de inserção de cateteres cobertos pelo CGCHX. Porém, análises de bactérias coletadas de sítios de inserção cobertos por curativos sem clorexidina também evidenciaram altas taxas deste gene, sugerindo que o uso do CGCHX por si só não está associado ao aumento destes genes neste local da pele, e sim na pele da maioria dos pacientes hospitalizados ${ }^{10}$.

Outro aspecto importante diz respeito ao tempo de exposição ao CGCHX. Quanto maior o tempo de exposição ao curativo, maior a prevalência de genes de tolerância à clorexidina. Pacientes com exposição ao CGCHX maior que 168 horas apresentaram maior prevalência dos genes de tolerância à clorexidina quando comparados aos pacientes com tempo de exposição menor que 72 horas $(p=0,04) .^{10}$

A partir do exposto, percebe-se a importância do conhecimento sobre o cuidado com o sítio de inserção do CVC mediante a exposição dos pacientes aos ambientes hospitalares, onde o crescimento de cepas multidrogas resistentes é cada vez maior e a suscetibilidade destes microrganismos aos agentes microbicidas é pouco conhecida.

Dentre as limitações deste estudo está o fato do estudo ter sido desenvolvido num hospital de ensino nível terciário onde comumente há a ocorrência maior de infecções por diferentes tipos de microrganismos, o delineamento utilizado que não permite afirmar relação de causa e efeito e o pequeno número de participantes.

Em relação às contribuições para a prática clínica, sugere-se que o curativo impregnado com 
antisséptico seja considerado uma medida de prevenção de infecção relacionada ao CVC, porém não deve ser considerada única estratégia para evitar o crescimento bacteriano em pacientes críticos.

\section{CONCLUSÃO}

O crescimento bacteriano foi maior nos pacientes em uso CGCHX. Apesar disto já ter ocorrido em outros estudos publicados, este fato é preocupante, pois pode levar à resistência microbiana não apenas aos antimicrobianos, mas também ao antisséptico clorexidina, que é o padrão atual para preparações cutâneas antes da inserção do CVC.

São necessárias novas pesquisas a esse respeito, pois uma provável resistência de microrganismos à clorexidina e antimicrobianos pode dificultar o tratamento de infecções relacionadas a cateteres intravasculares.

\section{CONFLITO DE INTERESSES}

Ao autores declaram que não há conflito de interesses.

\section{FONTE DE FINANCIAMENTO}

O projeto foi financiado pela Coordenação de Aperfeiçoamento de Pessoal de Nível Superior (CAPES).

\section{REFERÊNCIAS}

1. Centers for Diseases Control and Prevention (CDC). Bloodstream infection event (central line-associated bloodstream infection and non-central line-associated bloodstream infection) [Internet]. Atlanta: Centers for Diseases Control and Prevention; 2020 [updated 2020 Jan]. Available from: https://www.cdc.gov/nhsn/pdfs/ pscmanual/4psc_clabscurrent.pdf

2. O'Grady NP, Alexander M, Burns LA, Dellinger EP, Garland J, Heard SO, et al. Guidelines for the prevention of intravascular catheter-related infections. Am J Infect Control 2011; 39(4 Suppl 1):S1-34. https://doi. org/10.1093/cid/cir257

3. Webster J, Gillies D, O'Riordan E, Sherriff KL, Rickard CM. Withdrawn: gauze and tape and transparent polyurethane dressings for central venous catheters. Cochrane
Database Syst Rev 2016; (5):CD003827. https:// doi.org/ 10.1002/14651858.CD003827

4. Ullman AJ, Cooke ML, Mitchell M, Lin F, New K, Long DA, etal. Dressings and securement devices for central venous catheters (CVC). Cochrane Database Syst Rev 2015; (9):CD010367. https:// doi.org/10.1002/14651858. CD010367.pub2

5. Bashir MH, Olson LK, Walters SA. Suppression of regrowth of normal skin flora under chlorhexidine gluconate dressings applied to chlorhexidine gluconate-prepped skin. Am J Infect Control 2012;40(4):344-8. https://doi.org/10.1016/j.ajic.2011.03.030

6. Jeanes A, Bitmead J. Reducing bloodstream infection with a chlorhexidine gel IV dressing. Br J Nurs 2015; 24(19): S14-9. https://doi.org/10.12968/bjon.2015.24. Sup19.S14

7. Safdar N, O'Horo JC, Ghufran A, Bearden A, Didier ME, Chateau $D$, et al. Chlorhexidine-impregnated dressing for prevention of catheter-related bloodstream infection: a meta-analysis. Crit Care Med 2014; 42(7):170313. https://doi.org/10.1097/CCM.0000000000000319

8. Margatho AS, Ciol MA, Hoffman JM, Reis PED, Furuya RK, Lima DAFS, et al. Chlorhexidine-impregnated gel dressing compared with transparent polyurethane dressing in the prevention of catheter-related infections in critically ill adult patients: A pilot randomised controlled trial. Aust Crit Care 2019;471-478. https://doi.org/10.1016/j.aucc.2018.11.001

9. Kawamura H, Takahashi N, Takahashi M, Taketomi A. Differences in microorganism growth on various dressings used to cover injection sites: inspection of the risk of catheter-related bloodstream infections caused by Gram-negative bacilli. Surg Today 2014; 44(12):233944. https://doi.org/10.1007/s00595-014-0935-z

10. Choudhury MA, Sidjabat HE, Rathnayake IU, Gavin $\mathrm{N}$, Chan RJ, Marsh N, et al. Culture-independent detection of chlorhexidine resistance genes qacA/B and $\mathrm{smr}$ in bacterial DNA recovered from body sites treated with chlorhexidine-containing dressings. J Med Microbiol 2017; 66(4):447-53. https:// doi.org/10.1099/ jmm.0.000463

11. Carty N, Wibaux A, Ward C, Paulson DS, Johnson P. Antimicrobial activity of a novel adhesive containing chlorhexidine gluconate ( $\mathrm{CHG}$ ) against the resident microflora in human volunteers. J Antimicrob Chemother 2014; 69(8):2224-9. https://doi.org/10.1093/jac/ dku096

12. Carrer S, Bocchi A, Bortolotti M, Braga N, Gilli G, Candini $M$, et al. Effect of different sterile barrier precautions and central venous catheter dressing on the skin colonization around the insertion site. Minerva Anestesiol 2005;71(5):197-206. https://www.minervamedica.it/ en/journals/minerva-anestesiologica/article.php?co$d=$ R02Y2005N05A0197

13. Gerçeker GÖ, Yardımcı F, Aydınok Y. Randomized controlled trial of care bundles with chlorhexidine dressing and advanced dressings to prevent catheter-related 
bloodstream infections in pediatric hematology-oncology patients. Eur J Oncol Nurs 2017; 28:14-20. https:// doi.org/10.1016/j.ejon.2017.02.008

14. Biehl LM, Huth A, Panse J, Kramer C, Hentrich M, Engelhardt $M$, et al. A randomized trial on chlorhexidine dressings for the prevention of catheter-related bloodstream infections in neutropenic patients. Ann Oncol 2016;27(10):1916-22. https://doi.org/10.1093/annonc/mdw275

15. Düzkaya DS, Sahiner NC, Uysal G, Yakut T, Çitak A. Chlorhexidine-impregnated dressings and prevention of catheter-associated blood- stream infections in a pediatric intensive care unit. Crit Care Nurse $2016 ; 36(6)$ : e1e7. https://doi.org/10.4037/ccn2016561

16. Wang HX, Xie SY, Wang $H$, Chu HK. The effects of chlorhexidine dressing on health care-associated infection in hospitalized patients: a meta-analysis. Iran J Public Health 2019; 48(5):796-807. https://www.ncbi. nlm.nih.gov/pmc/articles/PMC6717407/

17. Eggimann $\mathrm{P}$, Pagani JL, Dupuis-Lozeron E, Ms BE, Thévenin $\mathrm{MJ}$, Joseph $\mathrm{C}$, et al. Sustained reduction of catheter-associated bloodstream infections with enhancement of catheter bundle by chlorhexidine dressings over 11 years. Intensive Care Med 2019;45(6):823-33. https://doi.org/10.1007/s00134-019-05617-x

18. Timsit JF, Schwebel C, Bouadma L, Geffroy A, Garrouste-Orgeas $M$, Pease $S$, et al. Chlorhexidine impregnated sponges and less frequent dressing changes for prevention of catheter-related infections in critically ill adults: a randomized controlledtrial. Jama 2009;301(12):123141. https://doi.org/10.1001/jama.2009.376

19. Timsit JF, Mimoz O, Mourvillier B, Souweine B, Garrouste-Orgeas $M$, Alfandari $S$, et al. Randomized controlled trial of chlorhexidine dressing and highly adhesive dressing for preventing catheter-related infections in critically ill adults. Am J Respir Crit Care Med 2012;186(12):1272-8. https://doi.org/10.1164/rccm. 201206-10380C

20. Wei L, Li Y, Li X, Bian L, Wen Z, Li M. Chlorhexidine-impregnated dressing for the prophylaxis of central venous catheter related complications: a systematic reviewand meta-analysis. BMC Infect Dis 2019;19(1):429. https://doi.org/10.1186/s12879-019-4029-9

21. Marschall J, Mermel LA, Fakih M, Hadaway L, Kallen A, O'Grady NP, et al. Strategies to prevent central line-associated bloodstream infections in acute care hospitals: 2014 update. Infect Control Hosp Epidemiol 2014;35(Suppl 2):S89-107.

22. Koljalg S, Naaber $P$, Mikelsaar M. Antibiotic resistance as an indicator of bacterial chlorhexidine susceptibility. J Hosp Infect 2002; 51(2):106-13. https://doi. org/10.1053/jhin.2002.1204

23. Lima MFP, Borges MA, Parente RS, Victória Júnior RC, Oliveira ME. Staphylococcus aureus e as infecções hospitalares - revisão de literatura. UNINGÁ Rev 2015;21(1):32-9. http://revista.uninga.br/index.php/ uningareviews/article/view/1616>. 
